\title{
As avaliações externas, a formação de professores e as políticas públicas: experiências da primeira década de um grupo de pesquisa em Educação em Ciências
}

\section{External evaluations, teacher training and public policies: experiences from the first decade of a research group in Science Education}

Las evaluaciones externas, formación docente y políticas públicas: experiencias de la primera década de un grupo de investigación en Educación Científica

\author{
Luiz Caldeira Brant de Tolentino-Neto (luiz.net@ufsm.br) \\ Universidade Federal de Santa Maria - UFSM \\ Jaiane de Moraes Boton (jaiambbio@gmail.com) \\ Universidade Federal de Santa Maria - UFSM
}

Resumo: O campo de pesquisa em educação em ciências no Brasil iniciou-se na década de 1970 e passou por grandes mudanças nestes cinquenta anos, dentre elas seu espalhamento por diversas regiões do país e a ampliação das temáticas investigadas. Dentro desse contexto, esse artigo descreve e reflete, em um texto autobiográfico a quatro mãos, sobre o surgimento e atuação de um grupo de pesquisa no Rio Grande do Sul, com foco nas políticas públicas de currículo, formação de professores e avaliações externas. A formação de pesquisadores, a articulação entre campos de pesquisa e a consolidação de um coletivo de referência na região central do estado gaúcho mostram-se como principais resultados deste esforço.

Palavras chaves: Educação em Ciências; Políticas Públicas; Formação de Professores; Avaliações Externas.

\begin{abstract}
The field of research in science education in Brazil began in the 1970s and has undergone major changes in these fifty years, among them its spread across several regions of the country and the expansion of the themes investigated. Within this context, this article describes and reflects, in an autobiographical text by four hands, about the emergence and performance of a research group in Rio Grande do Sul, focused on public policies of curriculum, teacher training and external evaluations. The training of researchers, the
\end{abstract}

Recebido em: 30/05/2021

Aceite em: 13/08/2021 
articulation between fields of research and the consolidation of a collective of reference in the central region of the state of Rio Grande do Sul are shown as the main results of this effort.

Key words: Science Education; Public Policies; Teacher Training; External Evaluations.

Resumen: El campo de la investigación en la educación de las ciencias en Brasil se inició en la década de 1970 y ha sufrido grandes cambios en estos cincuenta años, entre ellos su extensión por varias regiones del país y la ampliación de los temas investigados. En este contexto, este artículo describe y reflexiona, en un texto autobiográfico a cuatro manos, sobre el surgimiento y la actuación de un grupo de investigación en Rio Grande do Sul, centrado en las políticas públicas de currículo, formación docente y evaluaciones externas. La formación de investigadores, la articulación entre campos de investigación y la consolidación de un colectivo de referencia en la región central del estado de Rio Grande do Sul se muestran como los principales resultados de este esfuerzo.

Palabras clave: Educación en Ciencias; Políticas Públicas; Formación del Profesorado; Evaluaciones Externas.

\section{HISTÓRICO DA PESQUISA EM EDUCAÇÃO EM CIÊNCIAS NO BRASIL}

A história do surgimento e progresso da pesquisa em educação em ciências no Brasil é um amplo campo de narrativas e de reflexões, mas cabe nesse texto uma breve contextualização, ainda que repleta de abreviações, lacunas e saltos cronológicos.

É nas décadas de 1960 e 1970 que têm início no país as primeiras pesquisas sistemáticas e perenes sobre educação em ciências decorrentes - sobretudo - dos convênios bilaterais de formação de pesquisadores (como o MEC-USAID). Ainda que com forte viés colonizador e tecnicista (fortemente impregnado por um caráter profissionalizante segundo Borges e Lima, 2007), convênios como este permitiram o intercâmbio e a formação dos primeiros pesquisadores brasileiros especialistas em ensino de ciências e matemática. Prevalecia a concepção positivista e salvacionista de ciência, que ao ser popularizada traria solução a grandes problemas além de prever e evitar outros tantos. Uma materialização icônica dessa época são os projetos - transformados em livros - de Física (Physical Science Study Commitee - PSSC), de Biologia (Biological Science Curriculum Study - BSCS) e de Química (Chemical Bond Approach - CBA). É também nesse período histórico que se 
inauguram no Brasil centros e museus de ciência (como a Fundação Brasileira para o Desenvolvimento do Ensino de Ciências - Funbec/Ibeec) e algumas das mais antigas sociedades e entidades de pesquisa, como a SBPC (1948), SBF (1966) e SBQ (1977). Os primeiros cursos de pós-graduação datam desse mesmo intervalo histórico, os programas de Ensino de Física da Universidade de São Paulo (USP) e da Universidade Federal do Rio Grande do Sul (UFRGS).

Nas décadas seguintes, em período de redemocratização política no Brasil, o Ensino de Ciências passa de uma concepção de ciência como neutra para uma visão interdisciplinar e voltada para a cidadania, segundo Krasilchik (2008). Esse momento marca o nascimento de novas importantes entidades, fundadas por pesquisadores de 'segunda geração' e que reúnem, desde então, as comunidades acadêmicas de cada uma de suas áreas, como a ABRAPEC e SBEnBio (fundadas em 1997) e a SBEM (de 1988). O movimento que se inicia com ensino de física se expande para outras áreas científicas e cria subáreas, é também quando ocorrem os primeiros grandes eventos nacionais reunindo pesquisadores, professores e acadêmicos do ensino. Em inevitável paralelo, surgem novos programas de pós-graduação em ensino de ciências e matemática e os primeiros periódicos dedicados a este campo de pesquisa, com destaque para a Revista Brasileira de Ensino de Física (1979), o Caderno Brasileiro de Ensino de Física (1984) e o Boletim de Educação Matemática (Bolema) de 1985.

O Rio Grande do Sul ocupa um lugar de pioneirismo na pesquisa em educação/ensino de ciências e matemática ao abrigar, na UFRGS-Porto Alegre a pós-graduação em Física modalidade Ensino de Física em 1967. Desde então surgiram outros programas de formação de pesquisadores na área, com destaque para aqueles domiciliados na PUCRS, UNIJUÍ e FURG. É dessas primeiras gerações de pesquisadores que se registram nomes importantes como Otávio Aloisio Maldaner, Roque Moraes, Marco Antônio Moreira, Plinio Fasolo, Ático Chassot, Maria do Carmo Galiazzi, João Batista Harres, Maria Cristina Pansera de Araújo, Maria Lúcia Castagna Wortmann, Maria Inés Copello dentre tantos outros.

A primeira década dos anos 2000 é inaugurada com o surgimento - notadamente pouco pacífico - na CAPES da área 46 - Ensino de Ciências e Matemática. Como pontuam Ramos e Silva (2014)

Recebido em: 30/05/2021

Aceite em: 13/08/2021 
a tradição, representada pela comunidade científica da área de Educação, encontrava-se em tensão com os pesquisadores da área de ensino das Ciências Naturais, que representava o novo, sendo essas duas comunidades divergentes entre si (p. 370).

Esse marco histórico abre a expansão e consolidação de programas de pós-graduação na área no país, ainda que fortemente concentrados nas capitais e regiões mais ricas dos estados.

Em 2011, em um processo polêmico com a nomeação de coordenadores pró-tempore, a CAPES transformou a área 46 em área de Ensino, abrigando um espaçoso espectro de interesses, desde o ensino de psicologia ao ensino de engenharias, passando pela saúde e direito. As principais entidades de ensino de ciências e matemática manifestaram-se contrárias ao que, segundo elas, prejudicaria a crescente produção de uma identidade para essa comunidade científica emergente.

a comunidade não compreende e não aceita tal decisão, tendo em vista o desenvolvimento da área e suas contribuições para o entendimento de questões relacionadas ao ensino e à aprendizagem de Ciências e Matemática no Brasil (SBEM, 2011, p. 2)

Esta segunda década dos anos 2000, também é marcada por políticas públicas (sobretudo federais) de expansão e democratização do acesso ao ensino básico com a intensa abertura de institutos federais (em 2009 o ensino médio passa a fazer parte da educação básica obrigatória) e superior, com a criação de novas universidades, ampliação da oferta de cursos e vagas (REUNI), reorganização dos processos seletivos de ingresso (SISU) entre outras. A visão de que desenvolvimento educacional leva a desenvolvimento econômico, bem como convergências políticas, levam esses investimentos a regiões antes ignoradas no mapa da educação superior brasileira.

Ato contínuo, novos concursos públicos nas IES (inflados pela criação de cursos superiores de licenciatura nos IF) acolhem os pesquisadores egressos desses cursos de formação de pesquisadores em ensino de ciências. Esse movimento leva a uma nova onda de filiação às entidades representativas, de abertura de novos programas de pós-graduação, à 'oxigenação' dos programas mais tradicionais e ao surgimento de novos periódicos e eventos. Concomitantemente, as políticas de investimento seguem se ampliando com o PIBID (Programa Institucional de Bolsas de Iniciação à Docência) e os mestrados profissionais em rede, como o ProfMat, ProfFis e ProfBio.

Recebido em: 30/05/2021

Aceite em: 13/08/2021 


\section{HISTÓRICO DO PPG - ASSOCIAÇÃO AMPLA}

A fim de situar o surgimento do Grupo de Pesquisa IDEIA, faremos um breve relato histórico do Programa de Pós-Graduação em Educação em Ciências: Química da Vida e Saúde (PPGECQVS). O PPGECQVS, surgiu em 2005 com curso de mestrado acadêmico e, em 2008, com o curso de doutorado.

O Programa é tributário da longa tradição do Departamento de Bioquímica da UFRGS em ações no campo da educação em ciências, em especial aquelas desenvolvidas junto com o Departamento de Bioquímica Médica do Instituto de Ciências Biomédicas da UFRJ. Das atividades voltadas à formação de pessoal em Educação em Ciências, por meio da equipe do Prof. Leopoldo de Meis surge na pós-graduação em Bioquímica da UFRGS, em 1993, a linha de Pesquisa "Estudos em Educação em Ciências".

As interações com professores da Faculdade de Educação e do Instituto de Química (UFRGS) deram origem, em 1996, a cursos de formação para professores e alunos do Ensino Médio da Rede Pública. Esta, bem sucedida, trajetória de pesquisas, publicações, cursos e eventos, levou à articulação que deu origem à proposta de criação do PPGQVS em 2004.

Essa articulação envolveu um esforço conjunto de professores de diversos departamentos em diferentes instituições, além do Departamento de Bioquímica, da Faculdade de Educação e do Instituto de Química (UFRGS), somaram-se, também, pesquisadores da Faculdade de Educação da FURG (Fundação Universidade Federal de Rio Grande) e dos Departamentos de Química, de Bioquímica e de Biologia da UFSM (Universidade Federal de Santa Maria).

O Programa, com corpo docente da UFRGS, FURG e UFSM, foi aprovado pela CAPES, em 12 de novembro de 2004, em nível de Mestrado, iniciando suas atividades no primeiro semestre de 2005. No final de 2008, passou a funcionar como um Programa em Associação Ampla, oferecendo a formação em nível de Mestrado e Doutorado. Tal Associação garante isonomia e autonomia entre as sedes (cada uma tem seu regulamento, seu processo seletivo e de credenciamento), prevalecendo a horizontalidade entre as Instituições de Ensino Superior (IES) - diferentemente do que ocorre em Programas em Rede, onde uma IES sedia/coordena o Programa.

Recebido em: 30/05/2021

Aceite em: 13/08/2021 
O PPG Educação em Ciências foi pioneiro nessa estrutura organizacional na Área de Ensino de Ciências e Matemática (antiga área 46), na qual garante aos alunos a livre circulação entre as instituições, ou seja, acesso às suas disciplinas e infraestrutura. Os professores orientadores credenciados em uma sede, também podem oferecer disciplinas, seminários, supervisão de orientação, em qualquer uma das sedes da Associação Ampla. Uma quarta sede se juntou ao grupo, em 2017, a Unipampa Campus Uruguaiana (Universidade Federal do Pampa), ampliando ainda mais abrangência do Programa na região Sul, desta vez próximo à fronteira, confirmando assim seu papel central na formação de recursos humanos e na geração de conhecimento na área de ensino de ciências no país.

O PPGECQVS é o único programa do Estado do Rio Grande do Sul com curso de doutorado gratuito na Área de Ensino de Ciências, tornando-se opção para aqueles professores e pesquisadores que desejam ampliar suas perspectivas profissionais sem arcar com os altos custos dos cursos particulares. Além disso, a Associação Ampla é, como dito no relatório de área da avaliação 2017, o maior formador de pesquisadores na área de Ensino do Brasil. Na primeira década de funcionamento foram concluídas 258 dissertações de mestrado e 190 teses de doutorado, contribuindo para a significativa mudança no quadro de recursos humanos. Como consequência, a Associação Ampla foi, no período da Quadrienal 2013-2016, o Programa que mais produziu artigos em periódicos Qualis dentre todo o grupo de programas da área de Ensino (Relatório da área de Ensino 2017).

É importante salientar que a inserção social do PPG não se faz apenas com a titulação de mestres e doutores, pois o programa organiza uma série de eventos científicos e de divulgação. Ademais, muitas de suas pesquisas envolvem cursos de formação continuada de professores e muitos de seus egressos são atuantes em secretarias municipais, direções e salas de aula da educação básica, além de ocuparem posições decisórias em sindicatos e associações de classe.

\section{O PPGECQVS SEDE UFSM}

Na UFSM, o PPG é vinculado ao Centro de Ciências Naturais e Exatas (CCNE). A primeira geração de orientadores é oriunda de pesquisas "de bancada", da chamada área dura. São biólogos, geneticistas, químicos e bioquímicos que associam suas pesquisas ao Recebido em: 30/05/2021 Aceite em: 13/08/2021 
desenvolvimento da educação, tanto básica quanto superior. No início da década de 2010, as políticas de expansão universitária trazem novos professores à UFSM, alguns deles oriundos dos cursos de formação em educação em ciências, emergentes na década anterior. Desta forma o corpo docente do PPG se amplia e se diversifica, e passa a agregar professores com formação em educação e pesquisas exclusivamente na área de ensino. Atualmente, o corpo docente equilibra-se entre esses dois perfis de professores.

Dentre os grupos de pesquisa estabelecidos no PPG da UFSM e com registro no Diretório de Grupos de Pesquisa do CNPq, estão: Métodos e Processos de Ensino e Aprendizagem de Ciências - MPEAC (2009); Grupo de Estudos em Nutrição, Saúde e Qualidade de Vida - GENSQ (2010); IDEIA - Educação em Ciências (2011); Educação em Ciências em Diálogo (2012); Grupo de Pesquisa em Ensino e Aprendizagem em Ciências e Matemática - GPEACIM (2014); Grupo de Estudos Transdisciplinares: Educação em Ciências (2018); e EMgep - Educação Matemática: grupo de estudos e pesquisas (2019).

\section{NASCIMENTO DO GRUPO IDEIA (2011-2015)}

O Grupo IDEIA, em sua primeira fase, era o acrônimo de "Grupo Interinstitucional Desempenho Escolar e Inclusão Acadêmica", e concebido a partir da aprovação o projeto Desempenho Escolar Inclusivo na Perspectiva Multidisciplinar no âmbito do Edital 038/2010/CAPES/INEP - Observatório da Educação - OBEDUC. O grupo nasceu da parceria entre pesquisadores de seis Instituições de Ensino Superior (IES) do país: Universidade Federal de Santa Maria (UFSM), Universidade Federal de Mato Grosso (UFMT), Universidade Federal de São Paulo (UNIFESP), Universidade de São Paulo (USP) e Universidade Federal de Sergipe (UFS).

As IES, em parceria com o Instituto de Pesquisas e Desenvolvimento Tecnológico (IPTI), buscaram empreender tecnologias e conhecimentos para reflexões sobre elaboração de testes de desempenho que fossem sensíveis à diversidade de modos de aprender. O Projeto tinha quatro linhas de pesquisa: (1) Estimativa da Influência dos Distúrbios de Aprendizagem nos Índices de Desempenho Escolar em Língua, Matemática e Iniciação à Ciência; (2) Estudo da influência da Tecnologia dos Meios de Testagem no Resultado Final de Testes de Desempenho em Língua, Matemática e Iniciação à Ciência - Influência da tecnologia em 
Testes de Avaliações Padronizadas; (3) Estudo da Correlação entre o Desempenho Escolar em Língua e Matemática e Iniciação à Ciência - Estudos da Correlação entre Desempenho escolar e Livro Didático; e (4) Produção de Materiais Formativos e Institucionais que contemplem o enfrentamento das Dificuldades de Aprendizagem, como Dislexia, Discalculia, Déficit de Atenção e Hiperatividade no processo de formação do professor pesquisador.

Nesses quatro anos de OBEDUC foram organizados seminários gerais anuais, e duas edições do Encontro Nacional sobre Distúrbios de Aprendizagem na Perspectiva Multidisciplinar, em 2011, em Itabaiana (SE) e, em 2013, em Santa Maria (RS). Organizamos, em 2011, um simpósio no IX ENPEC (Encontro Nacional de Pesquisa em Educação em Ciências) intitulado "Elaboração de Instrumentos para Avaliação de Desempenho Escolar: processo colaborativo de criação de itens", também levamos resultados das pesquisas a dois importantes encontros de pesquisadores na Europa, a X Conference of the European Science Education Research Association (ESERA) e o 9o. Congreso Internacional sobre Investigación en la Didáctica de las Ciencias, ambos em 2013.

Integrantes do Grupo participaram de diferentes eventos nacionais com apresentação de trabalhos: em 2011, do Encontro Regional de Ensino de Biologia - Região Sul (EREBIO Sul), em Londrina (PR), e do Seminário Internacional de Educação, em Cachoeira do Sul (RS); em 2012, do Encontro Nacional de Ensino de Biologia (ENEBIO), em Goiânia (GO); em 2013, Seminário Internacional de Políticas Públicas da Educação Básica e Superior; IV Encontro Estadual da União Nacional dos Conselhos Municipais de Educação/RS; VII Semana Acadêmica do Curso de Especialização em Gestão Educacional, em Santa Maria (RS); em 2013 e 2015, do ENPEC que ocorreram em Águas de Lindóia (SP) entre outros.

Dois livros foram lançados nesse período, um deles uma coleção de textos relacionados aos resultados do projeto "Desempenho Escolar Inclusivo" e outro com uma escrita autobiográfica que relata a formação de uma pesquisadora imersa em um grupo de pesquisa interinstitucional e multidisciplinar "O que me auto[trans]forma Pedagoga? Um caminho a partir de vivências em um grupo de pesquisa".

No decorrer da primeira fase do IDEIA na UFSM foram concluídas uma tese de doutorado, cinco dissertações de mestrado, uma monografia de especialização e um Trabalho de Conclusão de Curso.

Recebido em: 30/05/2021

Aceite em: 13/08/2021 
A tese de doutorado foi defendida, em 2015, pela então bolsista CAPES/INEP Observatório da Educação (OBEDUC/Edital 038/2010) Janaina Pereira Pretto Carlesso, atualmente docente da Universidade Franciscana. Intitulada "Os reflexos da aplicação de um planejamento interdisciplinar no ensino de Ciências: da prática docente ao desempenho do aluno" o trabalho descreve, tanto o processo de formação-reflexão de uma professora de anos iniciais, quanto analisa os impactos da atuação dessa docente no desempenho de seus alunos, em português e matemática. A grande contribuição da pesquisa foi revelar que, no seu contexto, investir - tempo de estudo e de atividades em sala de aula - no ensino de ciências contribui para melhores desempenhos em avaliações padronizadas de língua portuguesa e matemática.

Três das cinco dissertações tinham temática relacionada ao Livro Didático. A bolsista CAPES/INEP - OBEDUC Jaiane de Moraes Boton apresentou, em 2014, a dissertação intitulada "O Processo de Escolha do Livro Didático por Professores: a evolução do PNLD e seus efeitos no Ensino De Ciências" que analisou o efeito de 20 anos de distribuição de livros didáticos no processo de escolha por professores do ensino fundamental. A pesquisa deixou claro os critérios de escolha desses docentes, vinculados tanto a aspectos da avaliação editorial-pedagógica da obra (qualidade das imagens, pertinência das atividades), quanto a questões mais subjetivas como a influência dos professores mais experientes e das editoras.

No ano seguinte, a Bolsista CAPES/INEP OBEDUC Micheli Bordoli Amestoy apresentou a dissertação "Articulações entre os interesses dos alunos e livros didáticos: A voz do estudante na construção curricular de ciências" que expõe o desencontro entre os temas científicos de interesses dos jovens de 15 anos e o conteúdo dos materiais didáticos, ou seja, o que os alunos querem aprender não está nos livros texto.

No mesmo ano de 2015, a bolsista CAPES/DS Karine Bueno do Nascimento aborda um tema polêmico, apresentando a dissertação "Programa Nacional do Livro Didático e Sistemas Apostilados de Ensino: um diálogo mediado pelas evidências da Prova Brasil”. Com objetivo de analisar uma geração escolar do ensino fundamental a partir dos resultados obtidos na Prova Brasil, e comparar estes resultados entre escolas que utilizam livro didático com escolas que utilizam sistema apostilado de ensino, os dados revelam que o uso de apostilados não garante melhores resultados nos testes padronizados da Prova Brasil.

Recebido em: 30/05/2021

Aceite em: 13/08/2021 
Na sequência, Juliana Batista Pereira dos Santos (bolsista CAPES/INEP - OBEDUC) teve como objetivo de sua dissertação comparar o desempenho dos alunos na disciplina de matemática quando realizam testes em papel e testes em computador. O trabalho intitulado "Testes em papel versus testes em computador: o meio de realização influencia o desempenho dos alunos?" mostra que são necessários cuidados ao comparar os diferentes formatos de aplicação das provas, e que há significativas diferenças de desempenho em matemática entre alunos que fazem a prova em papel e no computador.

Encerrando o ano de 2015, outra bolsista CAPES/INEP OBEDUC, Natália Borba Possebon, apresenta a dissertação, posteriormente transformada em livro, "O que me auto [trans]forma pedagoga? Um caminho a partir de vivências em um grupo de pesquisa". Com reflexões sobre o currículo, em especial às questões que envolvem o Ensino de Ciências nos Anos Iniciais e as dificuldades de aprendizagem, tem como objetivo estimular um novo olhar a respeito da formação do pesquisador e a atuação profissional docente dessa etapa da educação básica.

Com o término do período vinculado ao Observatório da Educação, o grupo IDEIA ganha uma nova configuração, passando a ser um grupo estabelecido na UFSM, com autonomia e liderança local. Novas linhas de pesquisa vieram naturalmente com o término do financiamento CAPES/INEP OBEDUC e, sobretudo, com o amadurecimento deste grupo. Os esforços de pesquisa passaram a se concentrar em investigações sobre formação de professores, avaliações em larga escala e políticas públicas de currículo. O grupo se consolida como referência nesses assuntos, não apenas no PPG Educação em Ciências, mas com participações e cooperações em pesquisas com grupos de várias universidades, com destaque para Universidade Franciscana (UFN), ULBRA Canoas, UNIFESP Diadema, Universidade de São Caetano do Sul e UNIOESTE Cascavel.

\section{O ALVORECER DA SEGUNDA DÉCADA}

A segunda década do Grupo IDEIA inicia-se marcada pela troca de nome, que passa a ser IDEIA - Educação em Ciências, ampliando seu espectro de atuação ainda que concentrando suas pesquisas em 3 linhas: Políticas Públicas; Formação e Atuação de Professores, e Avaliações em Larga Escala.

Recebido em: 30/05/2021

Aceite em: 13/08/2021 
O grupo, formado por professores, mestrandos, doutorandos, egressos e alunos da graduação, consolida-se como uma verdadeira comunidade de prática, em que o engajamento é mútuo, os objetivos e o repertório são compartilhados (ainda que as pesquisas individuais sejam diversificadas) em relações horizontais ainda que tenhamos no grupo pesquisadores experientes, em formação e novatos, criando um senso de identidade e pertencimento.

Nesses últimos anos, os integrantes do grupo continuaram participando de eventos, locais, regionais, nacionais e internacionais, como por exemplo: em 2016, ENEBIO em Maringá (PR), IV Seminário Internacional de Políticas Públicas da Educação Básica e Superior, V Seminário Internacional de Gestão Educacional e X Semana Acadêmica do Curso de Especialização em Gestão Educacional da Universidade Federal de Santa Maria, do Encontro brasileiro da REDESTRADO, do Seminário Internacional de Políticas Públicas da Educação Básica e Superior, esses últimos em Santa Maria (RS); em 2017, Encontro Regional de Ensino de Ciências (EREC), Jornada Acadêmica Integrada da UFSM (JAI/UFSM), Semana de Investigación, todos em Santa Maria (RS); em 2018; ENEBIO, em Belém (PA); em 2019, do Conference of the European Science Education Research Association (ESERA) em Bologna/Itália; em 2020, do Congresso Nacional de Inovação e Popularização da Ciência (CNIPC), em Belo Horizonte (MG), do Salão Internacional de Ensino, Pesquisa e Extensão da UNIPAMPA: Salão de Pesquisa e Inovação; em 2021, ENEBIO, Fortaleza (CE) on-line, e Encontro Nacional da ANFOPE (ENANFOPE), on-line, entre outros.

Nesta fase, pós-Observatório da Educação, dissertações e teses foram finalizadas enquanto outras estão em andamento. Para uma melhor organização apresentaremos os trabalhos finalizados em blocos de acordo com a linha de pesquisa.

\section{Formação e Atuação de Professores}

No contexto de mudança, entre finalização do antigo IDEIA e a constituição do IDEIA - Educação em Ciências, em 2017, ocorreu a apresentação da dissertação de mestrado da Gracieli Dall Ostro Persich, intitulada "Projeto Investigativo Interdisciplinar Conexão Delta e as potencialidades do Ensino por Investigação no Ensino Médio", que elaborou dinâmicas educativas que serviram de subsídio para o estudo investigativo de corpos d'água por estudantes de escolas que vivem no entorno de recurso hídrico, bem como para o Recebido em: 30/05/2021

Aceite em: 13/08/2021 
entendimento de aspectos ambientais e sociais da localidade para compreender os conteúdos curriculares de forma vivencial, prática e investigativa. Esse trabalho culminou num projeto com a turma do $3^{\circ}$ ano do Ensino Médio Politécnico do Colégio Estadual Pedro II, de Santo Ângelo e concorreu à $3^{\mathrm{a}}$ edição do prêmio 'Respostas para o Amanhã', promovido pela Samsung com o apoio do Centro de Estudos e Pesquisas em Educação, Cultura e Ação Comunitária (CENPEC) e Unesco e ficou entre os cinco melhores da região Sul e os 25 mais destacados do Brasil, a escola recebeu como prêmio um notebook.

Preocupada com a formação continuada dos professores e com a dificuldade desses de se deslocarem e ter horários disponíveis, em função de sua carga horária, em 2016, a Keiciane Canabarro Drehmer-Marques apresentou a dissertação "Formação continuada para professores de biologia: avanços e desafios de um curso EAD" com o objetivo de desenvolver e avaliar cursos de formação continuada para professores de biologia através da modalidade de Educação a Distância (EAD).

A Aline Bona Omelczuk, em 2017, em sua dissertação "Prática como Componente Curricular - definições legais e sua expressão na Formação Inicial do professor de Ciências e Biologia" teve como objetivo analisar o Projeto Pedagógico de Curso do Curso de Licenciatura em Ciências Biológicas da UFSM, do campus de Santa Maria e as legislações nacionais vigentes sobre a formação de professores para a Educação Básica para entender de que forma as Práticas como Componentes Curriculares são definidas em documentos oficiais e desenvolvidas durante a formação inicial de professores de Ciências e Biologia.

Com dissertação intitulada "Uso dos espaços não-formais na educação básica: o Jardim Botânico da UFSM”, em 2018, Rithiele Facco de Sá teve como objetivo analisar quais os objetivos das escolas ao utilizarem os espaços não formais. Outro trabalho, nesse mesmo contexto, em parceria com a professora Maria do Rocio Fontoura Teixeira da UFRGS, o professor Luiz Caldeira Brant de Tolentino-Neto coorientou o trabalho da Michele de Souza Fanfa "Espaços de Educação não Formal: produções de saberes na Formação Inicial de Professores de Ciências e Biologia", em 2020, que objetivou compreender como os espaços de educação não formal são abordados nas licenciaturas de Ciências Biológicas de universidades federais do estado do Rio Grande do Sul (RS), enquanto local de produção de

Recebido em: 30/05/2021

Aceite em: 13/08/2021 
saberes e prática docente. Os frutos dessa pesquisa originaram produções em colaboração entre as duas universidades (FANFA et al., 2020)

Em mais uma parceria, agora com a professora Maria Rosa Chitolina, em 2016, o professor Luiz Caldeira Brant de Tolentino-Neto, coorientou Leonan Guerra, na dissertação "Diferentes atividades didáticas sobre animais peçonhentos em uma escola rural da região central do Rio Grande do Sul" que teve como objetivo investigar como o pluralismo didático pode ser trabalhado em sala de aula de forma que auxilie os alunos no ensino sobre animais peçonhentos e prevenção de acidentes.

Em 2019, Fábio Luis Krützmann apresentou a dissertação intitulada "A estrutura das representações sociais de estudantes de um curso de Ciências Biológicas sobre Biólogo e Professor" em que buscou investigar as estruturas das Representações Sociais dos estudantes do Curso de Ciências Biológicas da UFSM sobre as futuras profissões: professor e biólogo. Para tanto, buscou analisar as representações dos discentes como uma construção social, apoiadas nas identidades e no curso de graduação em comum.

O mesmo pesquisador, em sua investigação de doutoramento, busca as conexões entre as condições de trabalho do professor de ciências e suas práticas/práxis tendo em vista as peculiaridades dessa área do conhecimento, as formações iniciais e continuadas, e as imposições que a pandemia do COVID-19 trouxe às relações trabalhistas dentro das escolas de educação básica.

Por meio do Doutorado Interinstitucional (DINTER), que tem como objetivo viabilizar a formação de doutores fora dos centros consolidados de ensino e pesquisa, mediante uma parceria entre a Universidade Federal do Vale do São Francisco (UNIVASF) e a UFRGS, em 2018, Rosangela Vieira de Souza defendeu a tese intitulada "O Programa Institucional de Bolsas de Iniciação à Docência enquanto lócus de mobilização de saberes para a utilização das Tecnologias de informação e Comunicação no ensino de Ciências: um itinerário possível?", com objetivo de investigar as interrelações entre os bolsistas participantes do PIBID identificando possíveis contribuições para o uso das Tecnologias de Informação e Comunicação nas atividades de ensino-aprendizagem.

Também voltada para a formação de professores, Jaiane de Moraes Boton defendeu sua tese "Demandas e dilemas da Prática como Componente Curricular na formação de Recebido em: 30/05/2021

Aceite em: 13/08/2021 
professores de biologia", em 2019, com os objetivos identificar e discutir a pluralidade na formação de professores de Biologia no país, identificar e discutir as diferentes visões sobre a formação de professores de biologia, identificar e discutir as diferentes visões sobre a PCC e propor possíveis mudanças para os cursos de licenciatura em Ciências Biológicas.

A pesquisa de doutoramento de Gabriela Luisa Schmitz dá sequência ao estudo das práticas como componente curricular em cursos da área de Ciências da Natureza visando investigar como se expressam nas disciplinas de bioquímica em IES gaúchas e propondo reformas curriculares e estruturais que as aproximem tanto da legislação vigente quanto daquilo que é preconizado em pesquisas acadêmicas.

A aprovação do projeto CNPq "Ciência na Escola" (Chamada MCTIC/CNPq 05/2019 Programa Ciência na Escola), em 2019, trouxe ao grupo a parceria dos professores Eliziane Dávila do IF Farroupilha/São Vicente do Sul e do recém-doutor Daniel Morim Ocampo e um novo campo de investigação, a Educação STEM (Ciência Tecnologia Engenharia e Matemática). A primeira pesquisa de mestrado foi conduzida pela bolsista CAPES/DS Andressa Lopes Freitas com vistas a identificar os potenciais espaços escolares que se constituem como comunidades de prática.

Entre os anos de 2018 e 2019, o grupo IDEIA recebe sua primeira pesquisa de pósdoutoramento. O professor Cirlande Cabral da Silva do IFAM/Manaus realizou seu PósDoutorado, com bolsa PNPD-CAPES e sob supervisão do professor Luiz Caldeira. Com o título "Investigação do processo de ensino aprendizagem no curso de Licenciatura em Ciências Biológicas da UFSM a partir da Teoria Fundamentada" a pesquisa trouxe resultados não apenas publicados em artigos, mas sobretudo na formação de novos pesquisadores, com disciplinas ofertadas no PPG, coorientações e escritas colaborativas.

\section{Avaliações em Larga Escala}

Em 2019, fazendo uma ligação entre as linhas Avaliações em larga escala e Políticas Públicas Micheli Bordoli Amestoy defendeu a tese "Accountability: Política de avaliação externa e suas relações com os modos de regulação dos sistemas educacionais" com o objetivo analisar como as avaliações externas da educação básica influenciam as políticas públicas educacionais e quais os seus efeitos na atuação de professores e gestores. Cabe Recebido em: 30/05/2021

Aceite em: 13/08/2021 
destacar que esse doutorado foi realizado com período sanduíche na Universidade do Minho, em Portugal, sob a orientação da professora Laurinda Sousa Ferreira Leite e descortinou um amplo campo de pesquisa colaborativa sobre as políticas de accountability.

No mesmo ano, Daniel Morin Ocampo defendeu sua tese intitulada "As tipologias dos estudantes brasileiros em relação ao interesse em ciências e tecnologia: uma nova análise dos projetos ROSE e Barômetro Brasil’". Com rigorosidade estatística e os dados advindos das seções 'O que eu quero aprender' dos questionários ROSE (The Relevance of Science Education) e Barômetro no Brasil, Daniel definiu as tipologias de estudantes brasileiros frente aos seus interesses pela ciência e tecnologia, discutidas a partir de uma perspectiva socioeconômica e cultural.

Em seu doutorado Kauana Gehrke Tonin, com coorientação de Daniel Ocampo, explora mais uma vez os dados do ROSE-Brasil para refletir sobre o paradoxo observado entre os jovens brasileiros que, apesar de acharem a disciplina escolar Ciências interessante, preferem outros componentes curriculares e não optam por seguir carreiras científicas.

\section{Políticas Públicas}

Em 2021, sob coorientação da doutora Micheli Bordoli Amestoy, Kélli Renata Corrêa de Mattos (bolsista CAPES/DS) teve como objetivo acompanhar e refletir sobre o percurso de elaboração e implementação de políticas públicas de currículo para a educação básica e o ensino de ciências no município de Santa Maria/RS. A dissertação "Base Nacional Comum Curricular e o processo de construção do Documento Orientador Curricular de Santa Maria/RS: da prescrição à indução de Políticas Educacionais" descreve a construção desse documento histórico, tendo em vista toda sua conjuntura política, social e pedagógica.

A pesquisadora Micheli Amestoy renova seu vínculo formal com o Grupo IDEIA não apenas atuando nessa coorientação, mas como bolsista de estágio pós-doutoral (CAPES/PNPD), propondo-se analisar os sentidos de docência na BNCC em um estudo do contexto da prática de professores de ciências em formação/atuação com fundamentação no ciclo de políticas de Stephen Ball e colaboradores. Atou ainda como docente substituta no Departamento de Metodologia do Ensino (MEN/CE UFSM) e em disciplinas da pósgraduação sobre avaliações em larga escala e metodologia de pesquisa.

Recebido em: 30/05/2021

Aceite em: 13/08/2021 
Em perspectiva semelhante, a tese de doutorado de Deborah Carla Calegari destrincha as versões da BNCC na área de Ciências da Natureza, debruçada sobre o que motiva e o que ambienta as diferenças entre suas diferentes versões, não apenas dos pontos de vista político e pedagógico, mas também através do prisma filosófico/epistemológico e da comunicação.

O mestrado de Bruna Tafarel Silva (bolsista CAPES/DS) investe no estudo da reforma do Ensino Médio e sua correlação com o interesse dos jovens de Santa Maria pela ciência, trazendo importantes subsídios para as políticas públicas relacionadas, sobretudo, aos itinerários formativos no ensino médio.

\section{PERSPECTIVAS PARA A PESQUISA EM EDUCAÇÃO EM CIÊNCIAS}

O planejamento de ações de pesquisa é tarefa cotidiana dos envolvidos em grupos de pesquisa na pós-graduação, da mesma forma que o replanejamento e a reorganização devem ser constantes. Novas regras, novas exigências e cortes orçamentários já faziam parte do repertório de decisões a serem tomadas, mas a situação emergencial surgida em 2020 trouxe novas preocupações e também oportunidades.

A interrupção das atividades presenciais com a pandemia da COVID-19, motivou a inauguração do canal no YouTube do Grupo Ideia UFSM, em que realizamos transmissões ao vivo com o objetivo de divulgar pesquisas e reflexões do Grupo. Convidamos atuais e antigos participantes do grupo para exporem suas pesquisas e trabalhos como forma de retroalimentar as interações e divulgar os resultados de pesquisas e debates destes dez primeiros anos de IDEIA. Nos anos que se seguem, novas ações terão vitrine neste importante canal de comunicação e interação.

As parcerias entre instituições seguem sendo prioridades no grupo. O projeto $\mathrm{CNPq}$ Ciência na Escola traz resultados promissores e pactua o trabalho colaborativo com o GEMS Grupo de Estudo do Movimento STEM, domiciliado no Instituto Federal Farroupilha Campus São Vicente do Sul. A intenção é expandir sua abrangência a outros municípios da região central do Estado, privilegiando sempre a interação com a escola básica, sobretudo as de ensino médio. Com colegas da UNIFESP Diadema, o projeto é de aplicação do ROSE em território gaúcho, com projeção de desenhar um quadro representativo dos interesses desses

Recebido em: 30/05/2021

Aceite em: 13/08/2021 
jovens pelas ciências e tecnologia a fim de embasar novas pesquisas e subsidiar tomadas de decisões políticas.

Ações de extensão, sempre associadas às de pesquisa e ensino, já fazem parte do portfólio do Grupo com destaque para o projeto Toda Cidade Ensina. Iniciado, em 2020, com um financiamento de projeto de ensino da UFSM, o projeto surge com a intenção de levar ao público geral visitas virtuais e abordagens científicas em espaços de educação não formal. São vídeos, veiculados na televisão aberta e gratuita, feitos no Jardim Botânico da UFSM, Centro de Apoio à Pesquisa Paleontológica da Quarta Colônia (CAPPA UFSM) e Mantenedouro de Fauna São Braz em que abordamos temas frequentes nas salas de aula do ensino médio como nutrição vegetal, especiação e extinção. Um material complementar é oferecido aos professores, com sugestões de leitura, atividades e recursos extras. Em 2021, com um financiamento de extensão mais longo e com orçamento maior, daremos sequência à produção, agregando outros recursos audiovisuais como podcasts, vídeos virais para aplicativos e redes sociais.

Novas pesquisas chegam ao grupo, algumas vindas de recém ingressantes no PPG Educação em Ciências e outras propostas por pesquisadores residentes, fixados no Grupo. As parcerias internacionais, sobretudo com colegas latino-americanos vinculados à RIEC - Red Internacional de Investigación en Enseñanza de las Ciencias. A RIEC é "uma teia científica com interação, formação de pesquisadores, compartilhamento e produção de pesquisas de Pós-Graduação com temáticas relacionadas ao Ensino de Ciências (EC)", (LEMKE e SCHEID, 2021) e que ganham corpo com a articulação regional encampada por colegas de instituições de ensino do Rio Grande do Sul como UFFS, URI, UNIJUI e UPF.

Não se perde de vista as perspectivas de qualificação para colocação dos doutores em posições de pesquisadores em instituições de ensino superior, as pesquisas de pós-doc e as orientações contribuem para esse movimento, ao lado das publicações advindas de pesquisas em andamento ou já concluídas.

O que se vê, ao longo dos dez primeiros anos de existência de um grupo de pesquisa em educação em ciências nascido em um programa de pós-graduação de Ensino é, não apenas o amadurecimento das linhas de pesquisa e das produções intelectuais, mas, sobretudo, o 
constante ciclo de semeadura, cultivo, florescimento e colheita compartilhado com responsabilidade e generosidade por pesquisadores em diferentes estágios de maturação.

\section{REFERENCIAS}

BORGES, R.M.R.; LIMA, V.M.R. Tendências contemporâneas do ensino de Biologia no Brasil. Revista Eletrônica de Enseñanza de las Ciencias, v. 6, n. 1, 2007. Disponível em: <http://saum.uvigo.es/reec/volumenes/volumen6/ART10_Vol6_N1.pdf $>$ Acesso em 20 mai. 2020 .

BRASIL. Ministério da Educação. Coordenação de Aperfeiçoamento de Pessoal de Nível Superior (CAPES). Dados Básicos do Programa. Disponível em:

$<$ https://sucupira.capes.gov.br/sucupira/public/consultas/coleta/programa/viewPrograma.jsf?p opup=true\&cd_programa=42001013098P9 > Acesso em 20 mai. 2020.

FANFA, M.; MARTELLO, C.; GUERRA, L.; TOLENTINO NETO, L.; TEIXEIRA, M. Espaços de Educação Não Formal e Alfabetização Científica: um olhar sob a exposição do MAVUSP. Revista Insignare Scientia - RIS, v. 3, n. 5, p. 98-113, 18 dez. 2020.

KRASILCHIK, M Prática de Ensino de Biologia. $4^{\text {a }}$ ed. São Paulo: Editora da Universidade de São Paulo, 2008.

LEMKE, C.; SCHEID, N. M. A interdisciplinaridade e a investigação-ação na Rede Internacional de Investigação em Ensino de Ciências (RIEC). Revista Insignare Scientia RIS, v. 4, n. 4, p. 270-291, 20 jun. 2021.

NARDI, R.. A pesquisa em ensino de Ciências e Matemática no Brasil. Ciência \& Educação (Bauru) [online]. 2015, v. 21, n. 2, pp. I-V. Disponível em: <https://doi.org/10.1590/1516731320150020001> Acesso em: 16 mai.2021. ISSN 1980-850X.

RAMOS, C. R.; SILVA, J. A.. A Emergência da área de Ensino de Ciências e Matemática da CAPES enquanto comunidade científica: um estudo documental. Investigações em Ensino de Ciências. v. 19(2), pp. 363-380, 2014. Disponível em:

<https://www.if.ufrgs.br/cref/ojs/index.php/ienci/article/viewFile/84/59> Acesso em: 20 mai. 2021.

SOCIEDADE BRASILEIRA DE EDUCAÇÃO MATEMÁTICA. Boletim eletrônico. n. 3, agosto de 2011, p. 2-5. Disponível em: <www.sbem.com.br/files/Boletim03.pdf.> Acesso em 20 mai. 2020.

Recebido em: 30/05/2021

Aceite em: 13/08/2021 